\title{
A Bibliometric Analysis of Communication Education Research (1990-2020)
}

\author{
Meral Ozcinar ${ }^{{ }^{*}}$ \\ (iD) 0000-0002-0606-6305 \\ ${ }^{1}$ Radio, Television, and Cinema Department, Faculty of Communication, Usak University, Usak, TURKEY \\ * Corresponding author: meral.ozcinar@usak.edu.tr
}

Citation: Ozcinar, M. (2021). A Bibliometric Analysis of Communication Education Research (1990-2020). Online Journal of Communication and Media Technologies, 11(4), e202117. https://doi.org/10.30935/ojcmt/11084

ARTICLE INFO

Received: 26 May 2021

Accepted: 1 Jul 2021

\section{ABSTRACT}

Communication education has become an expansive field of study. The aim of this study is to reveal the historical development of the field of communication education, its intellectual base and the research trends in the field. Document co-citation and burst detection methods were used to determine subfields and research trends in communication education. Bibliometric analysis was conducted through articles and proceeding papers, which were published in the field of communication education between 1990-2020, indexed by the Web of Science. As a result of the research, the majority of the researches in the field of communication education are seen to be carried out by the USA and European countries, and the number of publications has increased especially in recent years. Communication education research is mostly on health education-related fields. Doctor-patient communication in the field of Oncology and functional communication training are the broadest subfields and current trends in the field.

Keywords: communication education, communication skills, co-citation analysis, health communication

\section{INTRODUCTION}

Communication problems have arisen since the first-day people learned how to communicate. Therefore, thoughts on how to solve these problems have led to the emergence of communication education. The historical roots of communication education as a formal study field go back to rhetorical strategies in ancient Greek and Roma. In the following centuries, classical rhetoric became the main part of higher education and religious institutions. As of today, communication education has become an expansive field of study (Morreale, Backlund, \& Sparks, 2014).

Today, both scholars from different academic fields and business leaders point out consistently that communication education is a prerequisite for success in many endeavors (Hunt, Wright, \& Simonds, 2014). In this context, communication education is included in the Common Core standards in the USA. Similarly, in 2013, the Association of American Colleges and Universities (AAC\&U) declared that communication education should be a part of general education curricula in Higher Education (Morreale et al., 2014).

The communication education field is becoming the focus of attention in more and more research fields (Morreale \& Pearson, 2008). However, communication education studies "are often conducted independently: Researchers tend to do their study, often with little attention to what others are doing and often with little integration with other scholars" (Mazer, 2020 p.2). Although we could not find any studies on the structure of the communication education field, what its subfields are if any, and the interaction between these subfields, Communication as a field has increasingly diversified into subfields since the 1970s (Bryant \& Pribanic-Smith, 2010). The different development paths followed by these subfields and their poor integration with each other are manifested in the internal structures of communication departments and the rather weak links between research areas (Calhoun, 2011). It was suggested that subfields discuss their concepts and experimental findings in the journals peculiar to their field and they do not discuss what their reflections on other subfields

Copyright (c) 2021 by authors; licensee OJCMT. This article is an open access article distributed under the terms and conditions of the Creative Commons Attribution License (http://creativecommons.org/licenses/by/4.0/). 
may be, therefore broad theoretical frameworks cannot be developed (Tenenboim-Weinblatt \& Lee, 2020). This situation prevents the formation of a common intellectual base. This makes it difficult for researchers and policymakers working in the field to have a grasp of the development of the field and possible future research trends (Rains et al., 2020). In this context, this study explore the development of the communication education field, its intellectual base, and research trends.

As a scientific field, communication education has shown rapid development after the 1970s (Morreale et al., 2014). However, the history of the field of communication education in the English language is considered to be mostly matched with the history of communication education organizations, journals, and researchers in the USA. The field of communication has emerged under the influence of theory and disciplinary traditions in the USA and Western Europe. The pioneers of this field are entirely from the USA and Western Europe, and the participation of other countries in the field and the "de-westernization" of the field as an identity are relatively new phenomena (Waisbord \& Mellado, 2014). There is no information available in the literature about the development of the field of communication education on this issue. In this context, one of the objectives of this research is to determine the distribution of studies in the Web of Science (WoS) database in the field of communication education by years, countries and subject categories.

\section{METHODOLOGY}

The development of scientific fields is possible through communication between researchers. Academic journals are the most important medium where academics communicate with their "invisible colleagues". In this medium, every scientist examines the studies conducted before him or her and reveals his or her studies by feeding on them (Liu et al., 2015). When the researcher cites a study written before him or her, he or she acknowledges the effect of this study on his or her study and establishes a cognitive link between the cited study and the study giving the citation (Small, 1973).

Bibliometric methods accept citation relationships as an indicator of scientific communication and try to determine the structures and research orientations of scientific fields by investigating these relationships (Small, 1973). Co-citation analysis methods are used to determine the structure and intellectual base of scientific fields. In the co-citation method, the number of times two documents cited in pairs in the same scientific research is considered as the measurement of similarity between these two documents' research perspectives or content. Documents that have high co-citation frequency form the research fronts or subfields of the field. Co-citation method has been widely used to investigate research themes, subfields, and progress in the intellectual structure of scientific fields, and their validity is acknowledged (Avila-Garzon et al., 2021; Nerur, Rasheed, \& Natarajan, 2008). In this study, the document co-citation analysis method was used to determine the structure of the communication education field. The burst detection method was used to determine research trends in the field.

\section{Data}

The data of this study were obtained from the WoS Core Collection which contains over 21,100 peerreviewed, high-quality scholarly journals published worldwide in over 250 sciences, social sciences, and arts \& humanities disciplines. The WoS, maintained by Clarivate Analytics, is considered a trusted and ideal data source for bibliometric studies. WoS database was for information retrieval purposes. However, it is largely acknowledged that without the WoS the development of bibliometrics "would certainly have been hampered" (Birkle et al., 2020, p. 368).

A topic search for TS=("learning communication") OR TS=("teaching communication") OR TS=("communication instruction") OR TS=("communication training") OR TS=("communication education") OR TS=("communication skills education") OR TS=("communication skills instruction") OR TS=("communication skills training") resulted in 3432 studies published between 1 January 1990 and 12 December 2020. Search results were filtered to just include articles and full-text conference proceedings and the contents of the remaining 3107 studies, such as title, abstract, author, keywords, and references exported as plain text. The data can be accessed from https://raw.githubusercontent.com/mozcinar/communication_education/main/ com_ed.txt 


\section{Data Analysis}

WoS citation analysis facilities were used to analyze time, space, and category distribution of communication education researches. CiteSpace was used for the analysis of intellectual structure and research trends of the field. CiteSpace Software (Version 5.7. R3) is a free Java-based application and created by Chaomei Chen. CiteSpace provides methods for clustering co-citation networks of any field and generates cluster labels using automatic cluster labeling methods such as tfidf. It also facilitates the analysis of research trends, and pivotal points in the evolution of a knowledge domain (Chen, 2006).

In this study, each cluster was lableded using tfidf algorithm. Term frequency-inverse document frequency" (tf-idf) is one of the most commonly used term weighting schemes in text classification problems. "TF-IDF works by determining the relative frequency of words in a specific document compared to the inverse proportion of that word over the entire document corpus. Intuitively, this calculation determines how relevant a given word is in a particular document" (Ramos, 2003, p. 2).

\section{Document Co-citation Analysis}

The co-citation analysis method, which creates the intellectual base of a field, is used as a way to determine the similarity between the document that is cited in that field. In this method, the number of co-occurrence of any two studies in the bibliography of other publications is considered as a measure of the similarity of the two documents. As the number of co-occurrence of different document/author/journal pairs in the literature increases, clusters begin to emerge. The elements in this cluster are similar in theme (Surwase et al., 2011).

There are some concepts that should be defined in the interpretation of co-citation networks. The first of these is the network centrality criterion, called betweenness centrality. Betweenness centrality can be defined as the number of times a node in a network is located on the shortest path (geodesic path) between other nodes. Nodes with high levels of betweenness centrality control communication on the network (Leydesdorff, 2007). Betweenness centrality can be a value between 0 and 1 . Citespace symbolizes nodes with a betweenness centrality value greater than 0.1 with a pink circle. In this representation, as the value of the betweenness centrality increases, the pink circle is drawn proportionally thicker (Chen et al., 2010).

Modularity (Q) and Silhouette (S) is used to evaluate the quality of clustering. Modularity represents to clarity or strength of distribution of the network. The modularity value of a network ranges from 0 to 1 and modularity values above 0.3 are considered as successfully identified cluster structure. The silhouette value is a measure of how similar a node in any cluster is to nodes in its cluster compared to nodes in other clusters. The silhouette value varies between -1 and +1 , and when the clusters that make up the network have an average silhouette value greater than 0.7 , it indicates that the clustering process is acceptable (Chen et al., 2009).

\section{Burst Detection}

Burst detection means that an event is unusually popular over a certain period of time. Citespace (Chen, 2006) uses Kleinberg's (2003) burst detection algorithm to detect periods of unusually increased interest in the specialty. Burst detection algorithm which can be used according to the frequency of the words in the abstract, keywords, or title, can also be used for the number of citations of the studies in the intellectual base of the field. In this study, the burst detection algorithm was used to detect the unusual changes in the number of citations of the studies cited in the field.

In Kleinberg's burst detection algorithm events, keywords or citations are observed at each time period, t. Algorithm identifies events with an unusually high frequency of occurance for observed time period (t). Kleinberg uses a probabilistic automaton whose states corresponds to the frequencies of observed event, citations in this case (for a detailed explanation of the algorithm please see the Kleinberg, 2013).

\section{RESULTS}

\section{Distribution of Communication Education Publications by Years and Countries}

When communication education studies in journals indexed by WoS are examined, 2699 (87\%) of 3107 publications included in this study were seen to be conducted by researchers from 8 countries. It is seen that 
Table 1. Main countries of publications' origin

\begin{tabular}{lccc}
\hline Country /Region & Centrality & Number of Articles & $\%$ \\
\hline USA & 0.74 & 1434 & 46 \\
England & 0.17 & 273 & 8 \\
Australia & 0.13 & 261 & 9 \\
Germany & 0.11 & 176 & 6 \\
Netherlands & 0.16 & 142 & 5 \\
Canada & 0.09 & 136 & 4 \\
China & 0.02 & 101 & 3 \\
Spain & 0.10 & 90 & 3 \\
\hline
\end{tabular}

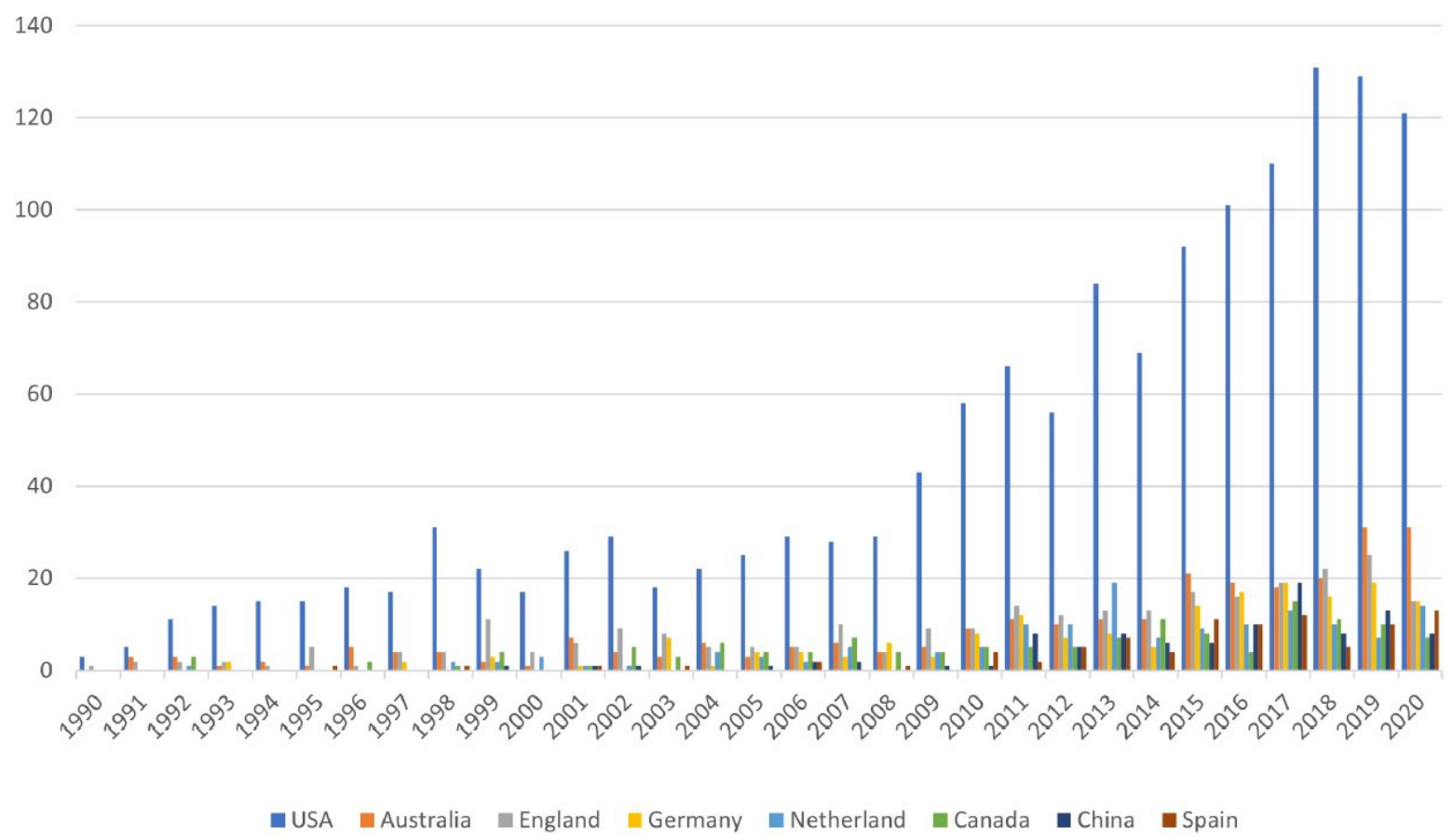

Figure 1. Contributions of countries to the communication education in terms of number of publications by year

1434 (46\%) of the 3107 publications examined were conducted in the USA, 273 (9\%) in England, and 261 (8\%) by researchers in Australia (see Table 1). When Table 1 is examined, the USA is seen to be in a central position in the field, has a very high betweenness centrality, and conducts joint studies with different countries. In the field, England, Australia, Germany, and the Netherlands are seen to be the other countries acting as a bridge.

Only 295 (9.4\%) studies were published in the field of communication education in the first 11 years within the examined 31-year period. This number was 662 (21\%) between 2001-2010 and 2150 (69\%) publications were made between 2011-2020. It is seen that 168 (57\%) of the studies in this period were carried out by researchers in the USA, 37 (13\%) in England, and 26 (9\%) by researchers in Australia. It is seen that 552 (83\%) of 662 articles published in 10 years between 2001-2010 were carried out by researchers in 8 countries. As seen in Figure 1, Among these countries, the USA was the most productive country with 307 (46\%) publications, England was second with 70 (10\%) publications, and Australia was third with 52 (8\%) publications. In the period from 2011 to December 2020, 2150 articles published in the field were examined, and 1802 (84\%) were found to be carried out by researchers in the top 8 countries. Among these countries, the USA is seen to rank first with 959 (45\%) publications, Australia ranks second with 183 (9\%) publications, and England ranks third with $132(8 \%)$ publications.

It is seen that a significant part of the studies in the field of communication education between 1990 and 2020 and published in journals indexed in WoS was carried out by researchers living in the USA (see Table 1). When the data are analyzed per decades, almost no scientific studies were seen to be conducted in the field of communication education in the 1990s, except in the USA, Australia, and England. By the 2000s, in addition to the USA, England, and Australia, European countries such as the Netherlands, Germany, and Spain, as well 


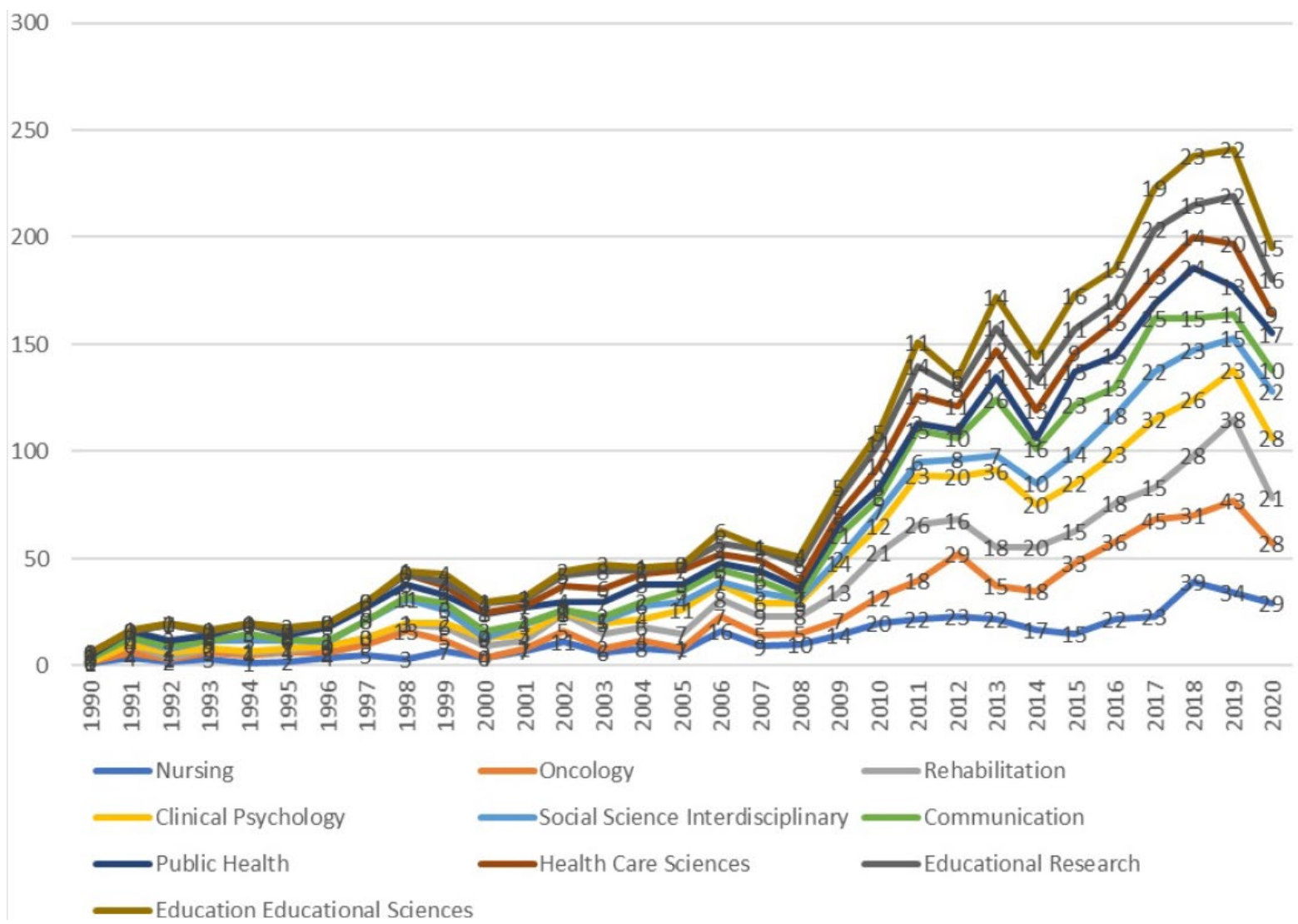

Figure 2. Top 10 subject categories in terms of number of publications

as China and Canada, communication education studies that were indexed in WoS began to be carried out. Another result of the study is that communication education studies have had a rapid increase especially in the last 5-10 years.

\section{Analysis of Subject Categories}

In the WoS subject category system, a journal can be assigned to more than one subject category. For example, Health Communication Journal is included in both Health Policy Services and Communication categories.

According to the subject category statistics from the WoS, two education categories are leading subject categories in the communication education research. As seen in Figure 2, Health Care Science is the third subject category in the field in regards to publication counts. Public Environment Occupational Health is fourth in the rankings with 333 publications. Communication is in the fifth largest subject category in the field. Social Science Interdisciplinary, Psychology-Clinical, Rehabilitation, Oncology, Nursing are among the main contributing subject categories in the field. As indicated from the findings, researchers in health and medicine related fields have made an outstanding contribution to the communication education literature.

\section{Intellectual Structure of Communication Education Field}

The references of 3107 communication education publications from 1990 to 2020 were analyzed with document co-citation analysis, using single year time slice. In this study, the 50 most cited studies in each slice at that time were included in the analysis. The resulting network consisted of 3888 nodes representing cited publications and 13655 co-citation links. After document co-citation analysis the network is divided into 32 cocitation clusters labeled by Citespace (see Figure 3).

In this study, the modularity of the network was calculated as 0.46 and the overall mean silhouette value was 0.95 which indicates the reliability of the results. The largest cluster (Cluster ID \#0) has 383 nodes and a silhouette value of 0.843 which indicates that this cluster perfectly differs from the others in the network. The average publication year of the studies in this cluster is 2002. Compared to other clusters, it can be said that 


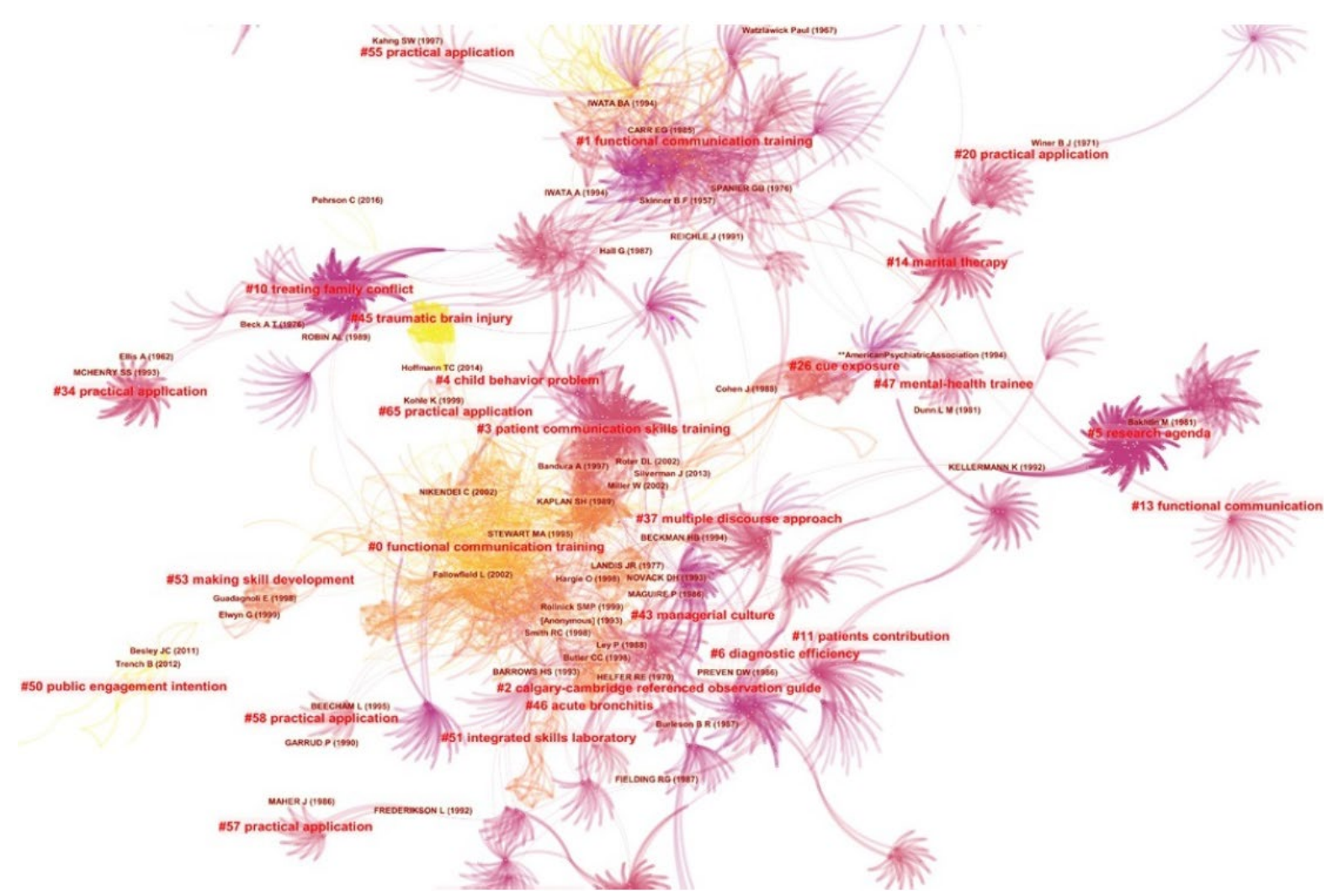

Figure 3. Document co-citation network

Note: In the figure, Co-citation links are colored according to the year they were created. While the oldest links are shown in dark purple, the newest links are shown in light yellow

the latest cluster in terms of formation is cluster \# 0 , thus reflecting one of the most popular themes in the field of communication education recently. The study giving the most citations to this cluster is the study of Schofield, Green and Creed (2008) with the title of "Communication skills of health-care professionals working in oncology-Can they be improved?". In this review study, researchers, through the literature, have compiled the importance of communication skills of healthcare professionals for patients and how they can improve the communication skills of healthcare professionals. The most cited study in cluster \#0 was the experimental study in which Fallowfield et al. (2002) investigated the effect of 3-day communication skills training on oncologists' communication skills, created using the Lipkin model, a learner-centered model. Steward's (1995) review study, which examined the relationship of patient-doctor communication with patient health outcomes, is the 2nd most cited study in this cluster. This cluster or sub-field consists of studies focused on ensuring patient communication with healthcare professionals, especially with doctors, its effect on the patient, and improving doctors' communication skills.

The second-largest cluster (Cluster ID \#1) has 305 nodes and a silhouette value of 0.927 . Cluster \#1 is labeled as "functional communication training" by Citespace. The publication years of the studies that make up this cluster are 1990 on average. Carr and Carlson's multi-component intervention study titled "Reduction of severe behavior problems in the community using a multicomponent treatment approach" (Carr \& Carlson, 1993), which aims to reduce the problematic behaviors of people with developmental disabilities in public spaces has been the study giving the most citations to Cluster \#1. The most cited study in this intellectual base is the one named "Reducing functional behavior problems through functional communication training" in which Carr and Durand (1985) tried to come up with an evidence-based guide for communication training. Iwata et al.'s (1994, p. 197) study, in which they described "the use of an operant methodology to assess functional relationships between self-injury and specific environmental events", was the second most cited study in Cluster \# 1. The main theme of this cluster is to reduce problematic behaviors with functional communication training. 
The silhouette value of the $3 r d$ Cluster (ID \#2) consisting of 158 nodes is 0.967 . The label of the cluster, in which the average publication year of the cited studies was 1984, was determined as "teaching" by Citespace. This cluster is one of the oldest themes in the field. The most active citer of this cluster is the study named "An appraisal of the current status of communication skills training in British medical schools" (Frederikson \& Bull, 1992), in which Frederikson and Bull examined the current status of CST in British medical schools. In the most cited study in the cluster, Maguire, Fairbairn, and Fletcher (1986) compared the quality of communication with the patient in the examination and diagnosis process, 5 years after the training of 20 doctors who received feedback training during medical education in the UK and a control group consisting of 20 doctors who did not receive any special training. The researchers revealed that the communication skills of the experimental group were not significantly different from the control group and that communication skills were poor in both groups. This cluster focus especially on the acquisition of CST in medical education in the UK.

The 4th largest cluster (ID \# 3), resulting from the document co-citation analysis, has 138 studies and a silhouette value of 0.97 . This cluster is labeled as "patient communication skills training" by Citespace. Cegala's study titled "A study of doctors' and patients' communication during a primary care consultation: Implications for communication training" (Cegala, 1997), in which he created a language coding scheme for the evaluation of doctor-patient communication was the study giving the most citations to this cluster. The study named "Assessing the Effects of Physician-Patient Interactions on the Outcomes of Chronic Disease", in which Kaplan, Greenfield and Ware (1989) examined the effect of doctor-patient communication on patients' health outcomes, was the most cited study in this cluster. This cluster focus on the results and effectiveness of CST provided to patients.

The 5th largest cluster consists of 129 studies and the silhouette value is 0.98 . This cluster is labeled as "application" with the tfidf algorithm in Citespace. The study giving the most citations to this cluster is Reed and Sollie's (1992) study named "Conduct Disordered Children: Familial Characteristics and Family Interventions", which they put forward by examining the familial characteristics of disordered young people and their families. Cluster's most cited study is Robin's (1981) study named "A controlled evaluation of problem-solving communication training with parent-adolescent conflict", in which he examined the effect of problem-solving communication training given to young people who have conflicts with their families on young-family conflicts. The focus of this cluster is communication education studies aimed at eliminating behavioral problems in children and adolescents.

\section{RESEARCH TRENDS}

The interests of researchers in scientific fields may focus on certain issues at certain times. This situation causes a rapid increase in the number of citations of the studies in the interested field or the number of words used from the keywords. Citation burst is used as an indicator for the research field that attracts more attention at that time (Chen, 2006). Citespace uses Kleinsberg's (2003) algorithm to detect statistically significant citation increases and gives the starting and ending year as well as the strength of the citation burst. So it is possible to determine the level and duration of interest in any study.

When Figure 4 is examined in terms of burst strength, the study titled "Using thematic analysis in psychology" in which Braun and Clark (2006), after positioning it according to other qualitative research methods, defined thematic analysis, one of the qualitative research methods, by taking into account its epistemological and ontological bases, is the study with the highest burst strength. Braun and Clark (2006) provided a guide for the application of thematic analysis in this study and discussed the advantages and disadvantages of the method. As seen in Figure 4, the citations received by the study are seen to have increased rapidly after 2014 and the citation burst continues.

Cluster \# 0's most cited study Fallowfield et al. (2002) was the second-highest study with 22.3 citation burst. This study attracted great attention in the field for 11 years between 2003 and 2014 and was one of the prominent publications in terms of citation burst duration. The study still seems to attract attention in the field. Similarly, the study in which Roter et al. (1995) showed that the communication skills training received by doctors contributed to the reduction of emotional distress experienced by the patients attracted a lot of 
References

Fallowfield L, 1998, J CLIN ONCOL, V16, P1961 ROTER DL, 1995, ARCH INTERN MED, V155, P1877 Fallowfield L, 2002, LANCET, V359, P650

Razavi D, 2003, J CLIN ONCOL, V21, P3141. Kurtz S, 2005, TEACHING LEARNING CO, V0, P0 Cegala DJ, 2002, MED EDUC, V36, P1004 Back AL, 2007, ARCH INTERN MED, V167, P453 Brown RF, 2008, ACAD MED, V83, P37

Baile W F, 2000, Oncologist, V5, P302 Maguire P, 2002, BRIT MED J, V325, P697 Roter D, 2002, PATIENT EDUC COUNS, V46, P243 Stiefel F, 2010, ANN ONCOL, V21, P204 Brunett PH, 2001, ACAD MED, V76, P390, Aspegren K, 1999, MED TEACH, V21, P563 Barth J, 2011, ANN ONCOL, V22, P1030 IWATA BA, 1994, J APPL BEHAV ANAL, V27, P197 Tiger JH, 2008, BEHAV ANAL PRACT, V1, P16 Berkhof M, 2011, PATIENT EDUC COUNS, V84, P152 Zolnierek KBH, 2009, MED CARE, V47, P826 Street RL, 2009, PATIENT EDUC COUNS, V74, P295 Braun V, 2006, QUAL RES PSYCHOL, V3, P0 Moore PM, 2013, COCHRANE DB SYST REV, V0, P0 Kissane DW, 2012, J CLIN ONCOL, V30, P1242 CARR EG, 1985, J APPL BEHAV ANAL, V18, P111 Curtis JR, 2013, JAMA-J AM MED ASSOC, V310, P2271

\begin{tabular}{lrl} 
Year Strength Begin End \\
1998 & 14.42 1999 & 2011 \\
1995 & 13.71999 & 2014 \\
2002 & 22.32003 & 2014 \\
2003 & 13.542005 & 2015 \\
2005 & 15.592006 & 2018 \\
2002 & 14.492006 & 2015 \\
2007 & 20.122009 & 2020 \\
2008 & 14.732009 & 2018 \\
2000 & 21.822010 & 2020 \\
2002 & 14.82010 & 2017 \\
2002 & 14.462010 & 2017 \\
2010 & 17.062011 & 2018 \\
2001 & 15.812011 & 2020 \\
1999 & 19.342012 & 2020 \\
2011 & 17.462012 & 2020 \\
1994 & 14.922012 & 2020 \\
2008 & 22.032013 & 2020 \\
2011 & 18.322013 & 2020 \\
2009 & 17.542013 & 2020 \\
2009 & 16.362013 & 2020 \\
2006 & 262014 & 2020 \\
2013 & 17.982014 & 2020 \\
2012 & 16.722014 & 2020 \\
1985 & 14.492015 & 2018 \\
2013 & 14.072016 & 2020 \\
\hline
\end{tabular}

Figure 4. Top 25 references with the strongest citation bursts in the co-citation network

interest from communication education researchers between 1994-2014. It is seen that the interest in the study continues in 2020 (see Figure 4).

The study of Tiger, Hanley, and Bruzek (2008), in which they reviewed and evaluated the Functional Communication Training researches and presented the best practice examples, ranks third in terms of citation burst strength. The citation burst process of the study is still ongoing. The study of Carr and Durand (1985), in which the functional communication training approach was first put forward, has also been another study achieving high citation burst in recent years. In line with all these findings, it can be said that functional communication themes will frequently find their place in research in the upcoming period.

\section{DISCUSSION AND CONCLUSION}

The changes that have taken place in the social and political fields in the last 30-40 years have made health communication education a part of the medical education curriculum in some parts of the world, especially in the USA and UK (Brown, 2012). In line with this, in-service communication training especially in the field of health and scientific researches conducted to make these training evidence-based have increased. The findings of this study also showed that Communication education research has been available in journals indexed by the WoS since the ' 90 s, but has increased rapidly especially in the last 10 years.

Almost half of the communication education researches is published by researchers in the USA. The second important focus area in this field has been European countries such as England, Germany, Netherlands, and Spain. Although the number of researches in the field is rapidly increasing, the distribution of them by country differs very little by years. This situation may be due to the differentiation of interest in communication education by country, or it may be related to international indexing and the publication policies of journals included in this indexing system. Goyanes (2020) investigated the editorial boards of 39 journals included in the first (Q1) and second (Q2) quartiles in the Journal Citation Report according to the nationalities of the researchers, and revealed that the majority of them were researchers living in the USA. In the research, it was revealed that $79.4 \%$ of the editorial board members of these journals live in the USA, UK, 
Canada, Australia, and Germany. The findings of Goyanes (2020) regarding the editorial board almost completely are in line with the nationality percentages of the researchers in this study.

Different researchers (Gunaratne, 2010; Waisbord, 2016) also stated that the studies in the field of communication are mostly dominated by western countries. This allows these countries to determine the research orientations, epistemological, methodological, and theoretical structure in the field (Gunaratne, 2010; Waisbord, 2016). Communication sciences in non-western countries have historically been influenced by different economic, political, and socio-cultural developments. The intellectual traditions of researchers in these countries are different from their western counterparts (Waisboard \& Mellado, 2014). Therefore, researchers in non-Western countries are not able to be as productive as their western counterparts in many areas of social sciences, within the journal and index system established in the west, such as the WoS (Gunaratne, 2010).

In this study, communication education studies were seen to be included in many subject categories. However, the main focus is on the fields of education, health, and communication. Health communication studies were seen to occupy an important place in the field of communication education. In general, the communication field is defined as a well-described, decentralized area that does not have a consolidated theoretical structure (Waisbord, 2016). It is known that the field of health communication is also an interdisciplinary field, and many researchers from different branches of health sciences such as nursing, medicine, veterinary medicine, pharmacy are conducting studies in this field outside of the communication field (Hoffmann-Longtin et al., 2020). The findings of this study showed that studies on communication education in the field of health has been conducted widely and for a long time. However, communication education studies are also in a decentralized state, and as Hoffmann-Longtin et al. (2020) claimed, the field creates a scattered image where the different specialty is formed for subjects such as cancer and medical education.

The cluster analysis results of the intellectual base of communication education research show that a very important part of the studies in the field was conducted in the subfields of health services. This result is the most interesting result of the study. Similar to the findings of this study, Morreale, Valenzano, and Bauer, (2017) revealed that health communication started to stand out among all the communication studies in 2008 (Morreale \& Peterson, 2008) and was the second most published theme in 2017. Researchers in the field of health communication can get funding more easily than other practical communication fields (Kim, Park, \& Shen, 2010). Besides, the field of health communication has much wider publication opportunities than other subfields of communication education (Kreps, Bonaguro, \& Query Jr, 2003). This may have caused the majority of communication education research to consist of studies in the field of health communication.

Today, health communication is a very large field of research that examines different levels and channels of communication in different contexts. Since the founding of the Therapeutic Communication Interest group of the International Communication Association (ICA) in 1972, the field has grown rapidly in terms of both institutional, the number of researchers, and funding provided (Kreps et al., 2003).

In this study, the studies on improving the patient-healthcare professional communication in the field of oncology have been revealed to be the most extensive and up-to-date subfield of the field. Cancer has been shown by different studies (Guenther, Gaertner, \& Zeitz, 2020; Kim et al., 2010; Nazione et al., 2013) to be one of the topics with most studies conducted. Considering the sensitivity of Oncology and the emotional burden it creates on the patient and the doctor, the well-being that good communication will provide for the patient and the doctor can be easily understood. In the last 3-4 decades, evidence-based practices are being developed to improve the quality of patient-doctor communication in the field of oncology through communication education research conducted at different levels from medical education to residency education. However, there is still a need for more work to be done to close the gap in patient-doctor communication (Pham, Bauer, \& Balan, 2014). The results of burst detection analysis used in this study showed that studies on doctor-patient communication in the field of oncology may continue to be the research trend of the next period in the field.

Traditionally, in the patient-healthcare provider interaction, the provider process is structured as a healthcare provider-oriented speech where the disease and treatment are explained (Taylor, 2009). However, in recent years, patient-centered communication has been conducted more widely among health 
communicators (Farin, Schmidt, \& Gramm, 2014). Ensuring patient participation in medical interviews is known to significantly contribute to the patient's ability to manage the process, to follow the treatment process, and to clinical outputs. Studies on improving the communication skills of patients have an important part in ensuring patient participation. Also, it is suggested that the communication skill of the patient affects the communication style of the doctor and the type and level of information he or she gives to the patient. The findings obtained in this study support the view that patient communication skills training should be one of the basic components of the health communication field (Cegala, 2006).

One of the research themes in the field of communication education is the studies that investigate the relationship between behavioral problems of children and adolescents, and the communication skills (of children and their environment, such as family, teacher, etc.) and aim to develop communicative intervention strategies (Kaiser \& Hester, 1997; Reed \& Sollie, 1992; Xiao, Li, \& Stanton, 2011). Two of the five broadest subfields of communication education focus on improving the psychological health of children and young people, with CST.

Starting from the idea that misbehavior in children was actually a form of communication 35 years ago, Edward Carr and Mark Durand published the first study on the Functional Communication Training Method. The main purpose of this study was to show how teaching children alternative communication styles that can be used in problem situations can improve their challenging behavior (Durand \& Moskowitz, 2015). This pioneering study of Carr and Durand (1985) on functional communication training received more than 1500 citations and the experimental study they applied was repeated in many different contexts with different variables (Durand \& Moskowitz, 2015). Functional communication training has been the second-largest subfield of communication education. Although this subfield is one of the first subfields of communication education, it still attracts a high level of attention. The presence of publications with high burst strength in this field can be interpreted as the field will continue to attract attention in the coming period.

\section{LIMITATIONS}

This study was conducted with communication education studies published in journals indexed by the WoS. In WoS, the number of journals in different subject areas can be disproportionate. This situation may have caused publications on some subject areas to be included more in the data set. Research results should be interpreted in consideration of this situation. Journals indexed in the WoS are mostly in English. Repeating this study with bibliometric data on publications in different languages may contribute to the emergence of a more comprehensive view of the field.

Author contributions: All authors were involved in concept, design, collection of data, interpretation, writing, and critically revising the article. All authors approve final version of the article.

Funding: The authors received no financial support for the research and/or authorship of this article.

Declaration of interest: Authors declare no competing interest.

Data availability: Data generated or analysed during this study are available from the authors on request.

\section{REFERENCES}

Avila-Garzon, C., Bacca-Acosta, J., Duarte, J., \& Betancourt, J. (2021). Augmented reality in education: An overview of twenty-five years of research. Contemporary Educational Technology, 13(3), ep302. https://doi.org/10.30935/cedtech/10865

Birkle, C., Pendlebury, D. A., Schnell, J., \& Adams, J. (2020). Web of Science as a data source for research on scientific and scholarly activity. Quantitative Science Studies, 1(1), 363-376. https://doi.org/10.1162/qss_a_00018

Braun, V., \& Clarke, V. (2006). Using thematic analysis in psychology. Qualitative Research in Psychology, 3(2), 77-101. https://doi.org/10.1191/1478088706qp063oa

Brown, J. (2012). Perspective: clinical communication education in the United Kingdom: some fresh insights. Academic Medicine, 87(8), 1101-1104. https://doi.org/10.1097/ACM.0b013e31825ccbb4

Bryant, J., \& Pribanic-Smith, E. J. (2010). A historical overview of research in communication science. The Handbook of Communication Science, 21-36. https://doi.org/10.4135/9781412982818.n2 
Calhoun, C. (2011). Plenary| Communication as social science (and more). International Journal of Communication, 5, 18.

Carr, E. G., \& Carlson, J. I. (1993). Reduction of severe behavior problems in the community using a multicomponent treatment approach. Journal of Applied Behavior Analysis, 26(2), 157-172. https://doi.org/10.1901/jaba.1993.26-157

Carr, E. G., \& Durand, V. M. (1985). Reducing behavior problems through functional communication training. Journal of Applied Behavior Analysis, 18(2), 111-126. https://doi.org/10.1901/jaba.1985.18-111

Cegala, D. J. (1997). A study of doctors' and patients' communication during a primary care consultation: Implications for communication training. Journal of Health Communication, 2(3), 169-194. https://doi.org/10.1080/108107397127743

Cegala, D. J. (2006). Emerging trends and future directions in patient communication skills training. Health Communication, 20(2), 123-129. https://doi.org/10.1207/s15327027hc2002_3

Chen, C. (2006). CiteSpace II: Detecting and visualizing emerging trends and transient patterns in scientific literature. Journal of the American Society for information Science and Technology, 57(3), 359-377. https://doi.org/10.1002/asi.20317

Chen, C., Chen, Y., Horowitz, M., Hou, H., Liu, Z., \& Pellegrino, D. (2009). Towards an explanatory and computational theory of scientific discovery. Journal of Informetrics, 3(3), 191-209. https://doi.org/10.1016/j.joi.2009.03.004

Durand, V. M., \& Moskowitz, L. (2015). Functional communication training: Thirty years of treating challenging behavior. Topics in Early Childhood Special Education, 35(2), 116-126. https://doi.org/10.1177/0271121415569509

Fallowfield, L., Jenkins, V., Farewell, V., Saul, J., Duffy, A., \& Eves, R. (2002). Efficacy of a Cancer Research UK communication skills training model for oncologists: A randomised controlled trial. The Lancet, 359(9307), 650-656. https://doi.org/10.1016/S0140-6736(02)07810-8

Farin, E., Schmidt, E., \& Gramm, L. (2014). Patient communication competence: Development of a German questionnaire and correlates of competent patient behavior. Patient Education and Counseling, 94(3), 342350. https://doi.org/10.1016/j.pec.2013.11.005

Frederikson, L., \& Bull, P. (1992). An appraisal of the current status of communication skills training in British medical schools. Social Science \& Medicine, 34(5), 515-522. https://doi.org/10.1016/0277-9536(92)902077

Goyanes, M. (2020). Editorial boards in communication sciences journals: Plurality or standardization?. International Communication Gazette, 82(4), 342-364. https://doi.org/10.1177/1748048518825322

Guenther, L., Gaertner, M., \& Zeitz, J. (2020). Framing as a Concept for Health Communication: A Systematic Review. Health Communication, 1-9. https://doi.org/10.1080/10410236.2020.1723048

Gunaratne, S. A. (2010). De-Westernizing communication/social science research: Opportunities and limitations. Media, Culture \& Society, 32(3), 473-500. https://doi.org/10.1177/0163443709361159

Hoffmann-Longtin, K., Kerr, A. M., Shaunfield, S., Koenig, C. J., Bylund, C. L., \& Clayton, M. F. (2020). Fostering Interdisciplinary Boundary Spanning in Health Communication: A Call for a Paradigm Shift. Health Communication, 1-9. https://doi.org/10.1080/10410236.2020.1857517

Hunt, S., Wright, A., \& Simonds, C. (2014). Securing the future of communication education: Advancing an advocacy and research agenda for the 21st century. Communication Education, 63(4), 449-461. https://doi.org/10.1080/03634523.2014.926016

Iwata, B. A., Dorsey, M. F., Slifer, K. J., Bauman, K. E., \& Richman, G. S. (1982). Toward a functional analysis of self-injury. Analysis and Intervention in Developmental Disabilities, 2(1), 3-20. https://doi.org/10.1016/02704684(82)90003-9

Kaiser, A. P., \& Hester, P. P. (1997). Prevention of conduct disorder through early intervention: A socialcommunicative perspective. Behavioral Disorders, 22(3), 117-130. https://doi.org/10.1177/019874299702200303

Kaplan, S. H., Greenfield, S., \& Ware Jr, J. E. (1989). Assessing the effects of physician-patient interactions on the outcomes of chronic disease. Medical Care, S110-S127. https://doi.org/10.1097/00005650198903001-00010 
Kim, J. N., Park, S. C., Yoo, S. W., \& Shen, H. (2010). Mapping health communication scholarship: Breadth, depth, and agenda of published research in health communication. Health Communication, 25(6-7), 487-503. https://doi.org/10.1080/10410236.2010.507160

Kleinberg, J. (2003). Bursty and hierarchical structure in streams. Data Mining and Knowledge Discovery, 7(4), 373-397. https://doi.org/10.1023/A:1024940629314

Kreps, G. L., Bonaguro, E. W., \& Query Jr, J. L. (2003). The history and development of the field of health communication. Russian Journal of Communication, 10, 12-20.

Leydesdorff, L. (2007). Betweenness centrality as an indicator of the interdisciplinarity of scientific journals. Journal of the American Society for Information Science and Technology, 58(9), 1303-1319. https://doi.org/10.1002/asi.20614

Liu, Z., Yin, Y., Liu, W., \& Dunford, M. (2015). Visualizing the intellectual structure and evolution of innovation systems research: a bibliometric analysis. Scientometrics, 103(1), 135-158. https://doi.org/10.1007/s11192-014-1517-y

Maguire, P., Fairbairn, S., \& Fletcher, C. (1986). Consultation skills of young doctors: Il--Most young doctors are bad at giving information. $B r$ Med J (Clin Res Ed), 292(6535), 1576-1578. https://doi.org/10.1136/bmj.292.6535.1576

Mazer, J. P. (2020). Beginning Communication Education's eighth decade. Communication Education, 1-3. https://doi.org/10.1080/03634523.2020.1838587

Morreale, S. \& Pearson, J. (2008). Why communication education is important: The centrality of the discipline in the 21 st century. Communication Education, 57, 224-240. https://doi.org/10.1080/03634520701861713

Morreale, S. P., Valenzano, J. M., \& Bauer, J. A. (2017). Why communication education is important: A third study on the centrality of the discipline's content and pedagogy. Communication Education, 66(4), 402422. https://doi.org/10.1080/03634523.2016.1265136

Morreale, S., Backlund, P., \& Sparks, L. (2014). Communication education and instructional communication: Genesis and evolution as fields of inquiry. Communication Education, 63(4), 344-354. https://doi.org/10.1080/03634523.2014.944926

Nazione, S., Pace, K., Russell, J., \& Silk, K. (2013). A 10-year content analysis of original research articles published in Health Communication and Journal of Health Communication (2000-2009). Journal of Health Communication, 18(2), 223-240. https://doi.org/10.1080/10810730.2012.688253

Nerur, S. P., Rasheed, A. A., \& Natarajan, V. (2008). The intellectual structure of the strategic management field: an author co-citation analysis. Strategic Management Journal, 29(3), $319 \mathrm{e} 336$. https://doi.org/10.1002/smj.659

Pham, A. K., Bauer, M. T., \& Balan, S. (2014). Closing the patient-oncologist communication gap: a review of historic and current efforts. Journal of Cancer Education, 29(1), 106-113. https://doi.org/10.1007/s13187013-0555-0

Rains, S. A., Keating, D. M., Banas, J. A., Richards, A., \& Palomares, N. A. (2020). The State and Evolution of Communication Research. Computational Communication Research, 2(2), 203-234. https://doi.org/10.5117/CCR2020.2.004.RAIN

Ramos, J. (2003, December). Using tf-idf to determine word relevance in document queries. In Proceedings of the first instructional conference on machine learning (Vol. 242, No. 1, pp. 29-48).

Reed, R. R., \& Sollie, D. L. (1992). Conduct disordered children: Familial characteristics and family interventions. Family Relations, 352-358. https://doi.org/10.2307/585203

Robin, A. L. (1981). A controlled evaluation of problem-solving communication training with parent-adolescent conflict. Behavior Therapy, 12(5), 593-609. https://doi.org/10.1016/S0005-7894(81)80132-3

Roter, D. L., Hall, J. A., Kern, D. E., Barker, L. R., Cole, K. A., \& Roca, R. P. (1995). Improving physicians' interviewing skills and reducing patients' emotional distress: a randomized clinical trial. Archives of Internal Medicine, 155(17), 1877-1884. https://doi.org/10.1001/archinte.1995.00430170071009

Schofield, N. G., Green, C., \& Creed, F. (2008). Communication skills of health-care professionals working in oncology-Can they be improved?. European Journal of Oncology Nursing, 12(1), 4-13. https://doi.org/10.1016/j.ejon.2007.09.005

Small, H. (1973). Co-citation in the scientific literature: A new measure of the relationship between two documents. Journal of the American Society for information Science, 24(4), 265-269. https://doi.org/10.1002/asi.4630240406 
Surwase, G., Sagar, A., Kademani, B. S., \& Bhanumurthy, K. (2011). Co-citation analysis: an overview. In Beyond Librarianship: Creativity, Innovation and Discovery, Mumbai (India), 16-17 September, 2011.

Taylor, K. (2009). Paternalism, participation and partnership-the evolution of patient centeredness in the consultation. Patient Education and Counseling,74(2), 150-155. https://doi.org/10.1016/j.pec.2008.08.017

Tenenboim-Weinblatt, K., \& Lee, C. J. (2020). Speaking Across Communication Subfields. Journal of Communication, 70(3), 303-309. https://doi.org/10.1093/joc/jqaa012

Tiger, J. H., Hanley, G. P., \& Bruzek, J. (2008). Functional communication training: A review and practical guide. Behavior Analysis in Practice, 1(1), 16-23. https://doi.org/10.1007/BF03391716

Waisbord, S. (2016). Translations | communication studies without frontiers? Translation and cosmopolitanism across academic cultures. International Journal of Communication, 10, 868-886.

Waisbord, S., \& Mellado, C. (2014). De-westernizing communication studies: A reassessment. Communication Theory, 24(4), 361-372. https://doi.org/10.1111/comt.12044

Xiao, Z., Li, X., \& Stanton, B. (2011). Perceptions of parent-adolescent communication within families: It is a matter of perspective. Psychology, Health \& Medicine, 16(1), 53-65. https://doi.org/10.1080/13548506.2010.521563

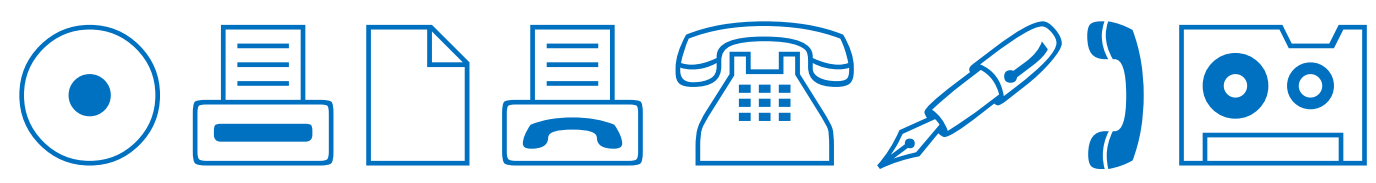

